\title{
INVESTMENT DECISIONS IN A FIRM AS THE PART OF BUSINESS FINANCIAL DECISION SYSTEM
}

\author{
Associate Proffessor PhD Melles Hagos Tewolde, Institute of Economics, Illyés Gyula College of \\ the University of Pécs, mhtewoldel@igyfk.pte.hu
}

\begin{abstract}
While the tools and techniques covered in this paper are discussed and demonstrated in details, the user must not be tempted to view them as the ends in themselves. It's simply not enough to master the techniques alone! Financial and economic analysis is both an analytical and judgment process which helps answering questions that have been carefully posed in management context. The process is at its best when the analyst's efforts are focused primarily on the structuring the issue and its context, and only secondary on the data manipulation.

Selecting the appropriate tools from the financial decisions is clearly an important part of the analytical task. Yet, experience has shown again and again that developing a proper perspective for the problem or issue is just as important as the choice of the tools themselves.

Apart from the providing specific numerical answers the "solutions" to financial problems and issue depends significantly on the points of view of the parties involved on the relative importance of the issue, and the nature and reliability of the information available.
\end{abstract}

Key words: strategic perspective, decisional framework, components of analysis, economic analysis methods.

JEL Codes:G10

The decision to invest resources is one of the significant drivers of the business financial system. Sound investments that implement well organized strategies are important to creating shareholders value, and must be analyzed both in proper context and sound analytical methods. Whether the decision involves committing resources to new facilities, a research and development project, marketing program, additional working capital, an acquisition, or investing in a financial instrument, an economic trade off must be made between the resources expended now and the expectation of future cash benefits to be obtained.

Analyzing the trade off is essentially a valuation process that makes an economic assessment of combination of positive and negative cash flow patterns. The task is difficult because it ideals with future conditions subject to uncertainties and risks - yet this valuation principle is common to all investments.

In other words, investing is incurring costs in order to gain benefit during the estimated life of the plant assets or current assets in the future. As a result investing should be assessed and analysis carefully with in the giving alternatives.

When we as individuals talk of costs and benefits, we naturally tend to consider only our own costs and benefits. To oversimplify, we select between alternative courses of action according to which has the greatest individual net benefits. Similarly, in evaluating various investment alternatives, firms tend to consider only those costs $\left(C_{0}\right)$ and benefits $(N P V)$ that flow to them.

Therefore the analysis of decisions about new investments involves a particularly complex set of issues and choices that must be resolved by management. These could be strategic perspective, decisional framework, components of the analysis, and economic analysis method. 
Therefore the business investment, in contrast to operational spending, are normally long term commitments of resources, they should always be made within the scope of the company's explicit strategy.

Moreover, most business investment projects have in common several significant components of analysis. These must be understood and made explicit, as well as comparable, in order to arrive at the best choice among different investment alternatives.

As the real of facts, the economic nature of the process requires that the analytical methods supporting the decision focus on the cash flow impact of investment.

\section{Strategic perspective}

Investment in tangible assets and intangible assets and other resources deployments made for the future economic gain should be the expression of company's strategy. It should be established by the management and should be evaluated periodically. During the investment and its life the expected economic condition, the outlook of the company's specific industry or business segment, competitive position of the company and competencies of the organization should be taken into the consideration.

A company may invest in new facilities for expansion, expecting that additional profits from additional volume will make the investment economically desirable. Investment may also be made for upgrading worn or outmoded faculties to improve cost effectiveness.

Some strategies call for entering new markets, which could involve setting up the entirely new facilities and associated working capital, or perhaps a major repositioning of existing facilities through rebuilding or through sale and reinvestment. In service business, expansion strategies could involve significant employee training outlays and electronic infrastructure investment. Other strategic proposal might involve establishing a research facility, justified on the basis of its potential for developing new products or processes. Business investment could also involve significant promotional outlays, targeted on the raising the company's market share over the long-term and, with it, the profit contribution from higher volume of operation.

The capital budgeting of the firm should be identifying, analyzing, and selecting the capital investment. The capital budgeting processes includes everything from a broad scoping of the ideas to very refined economic analysis. At the end, the company's capital budget normally contains an acceptable group of projects that individually and collectively are expected to provide economic returns meeting long-term management goals in support of shareholders value creation.

In an investment portfolio, cash disbursements are made in order to receive future inflows of cash in the form of dividends, interest, and eventually recovery of the principal through sale of the investment instruments - which over time may have appreciated or declined in the market value. In capital budgeting, the commitment of company funds is made in exchange for the future cash inflows from additional after tax profits and the potential recovery of portion of capital invested, or from the value of going business at the end of planning horizon.

However, the analogy carries only so far, in a typical company, managing investments is complicated by the need not only to select a portfolio of sound projects, but also in operate the facilities, service functions, or the assets deployed with the effectiveness.

If we follow the analogy between a capital budget and an investment portfolio to its logical conclusion, capital budgeting would ideally amount to arraying all business investment opportunities in the order of their expected economic returns, and choosing a combination that would meet the desired portfolio return within the constraints of risk and available funds. The theoretical concepts that have evolved around these issues rely heavily on portfolio theory, both in terms of risk evaluation and in the comparison between investment returns the cost of capital incurred in funding the investment. 
These concepts are highly structured and depend on a series of important underlying assumptions. Not easy to apply in practice, they continue to be the subject of much learned argument. In simple terms, the theory argues that the business investment - arrayed in declining order of attractiveness - should be accepted to the point at which incremental benefits equal incremental cost, given appropriate risk levels. in other words, the net present value should be zero.

The theory encounters several problems when applied in a practical setting. When capital budget is prepared, it's simply not possible to forecast all investment opportunities, because management faces a continuously revolving planning horizon over which new opportunities keep appearing, while known opportunities may fade as conditions change even more rapidly.

Next, capital budgets are prepared only once a year in most companies. As various timing lags are encountered, actual implementation may be delayed or even canceled because circumstances always change.

The last economic criteria, such as rate of return and cost of capital, are merely approximations. Moreover, they are not the sole basis for the investment decision. Instead, the broader context of strategy the competitiveness environment, the ability of management to implement the investment, organizational considerations, and other factors come into play as management weighs the risk of an investment against the potential economic gain. Thus there is nothing automatic or simple in arriving at decisions about the stream of potential investment that are continuously surfaced within a business organization.

\section{The decisional framework}

Effective analysis of business of business investment $\mathrm{s}$ requires that both the analyst and the decision maker be very conscious of and specific about the many dimensions involved. They need to set a series of ground rules to ensure that their results are thorough, consistent, and meaningful. The rules should consist of problem definition, nature of the investment; estimate the future costs and benefits, incremental cash flow, relevant accounting data, sunk costs and finally the time value of money.

Carefully defining the problem to be solved by investment, identifying any potential alternatives to the proposed action, are critically important to proper decision makings.

This elementary point is often overlooked, at times deliberately, when the desire to proceed with a favorite investment project overrides sound judgment. In most cases, at least two or three alternatives are available for achieving the purpose of an investment, and careful examination of the specific circumstances may reveal an even greater number. The simple diagram in Figure 6-1 can helps us to visualize the key options for deciding on which alternatives to pursue in an investment proposal.

For example, the decision of whether to replace a machine nearing the end of its useful life at first appears to be a relatively straightforward either/or problem. The most obvious alternative, as in any case, is to do nothing, that is, to continue patching up the machine until it falls apart. The ongoing, rising costs likely to be incurred with that option are compared with the expected cost pattern of a new machine when we decide whether or not to replace it. But the alternative of doing nothing exists for any investment project, and sound analysis requires that its implications be tested before proceeding.

There are some not-so-obvious alternatives. Perhaps the company should stop making the product altogether! This "go out of business" option should at least be considered-painful as it may be to think about-before new resources are committed.

The reasoning behind this seemingly radical notion is quite straightforward. While the improved efficiency of a new machine or a whole new facility may raise the product's profit performance from poor to average, there may indeed be alternatives elsewhere in the company that would yield greater profit from the funds committed. By going ahead with the replacement, an 
opportunity cost from losing a higher profit option might be incurred. In the interest of shareholder value creation, it might be better to redeploy all resources now devoted to the product instead of prolonging its substandard performance.

Morever, even if the decision to continue making the product is economically sound under prevailing conditions, there still are several additional alternatives open to management.

\section{Nature of the Investment}

Most business investments tend to be independent of each other, that is, the choice of any one of them doesn't preclude also choosing any other-unless there are insufficient funds available to do them all. In that sense, they can be viewed as a portfolio of choices. The analysis and reasoning behind every individual decision will be relatively unaffected by past and future choices. There are, however, circumstances in which investments compete with each other in their purpose so that choosing one will preclude the other. Typically, this arises when two alternative ways of solving the same problem are being considered. Such investment projects are called mutually exclusive. The significance of this condition will become apparent when we discuss the measures used to judge economic desirability. A similar condition can, of course, also arise when management sets a strict limit on the amount of spending, often called capital rationing, which will preclude investing in some worthy projects once others have been accepted.

Another type of investment involves sequential outlays beyond the initial expenditure. For example, any major capital outlay for plant and equipment usually also entails additional future outlays for major maintenance, upgrading, and partial replacement some years hence. These future outlays -to which the company is committing itself-should be considered when the initial decision is made. Another example is the introduction of a new product with high growth potential, where additional working capital and perhaps capacity expansions are a natural consequence of the decision to proceed.

The most logical evaluation of such investments comes from taking into account the whole pattern of major outlays recognizable at the time of analysis. If this isn't done, such a project may be viewed more favorably than a more straightforward one. Moreover, if the project is chosen, management may become trapped into having to approve unanticipated future outlays as they arise later-on the argument that these incremental funds are clearly justifiable because the project is " already in place". While that argument was originally not judged on its full implications, and under those conditions might not have been justifiable.

\section{Future Costs and Benefits}

As we stated earlier, one of the key principles in making investment decisions is that the economic calculations used to justify any business investment must be based on projections and forecasts of future revenues and costs. It's simply not enough to assume that the past conditions and experience, such as operating costs or product prices, will continue unchanged and be applicable to a new venture. While this may seem obvious, there's a practical temptation to extrapolate past conditions instead of carefully forecasting likely developments. The past is at best $\mathrm{s}$ rough guide and at worst irrelevant for analysis.

The success of a $\mathrm{n}$ investment whether the time horizon is two, five, ten, ad even twenty-five years, rests entirely on future events and the uncertainty surrounding them. It therefore behooves the analyst to explore as much as possible the likely changes from present conditions in the key variables relevant to the analysis. If potential deviations in several areas are large, it may be useful to run the analysis under different sets of assumptions, thus testing the sensitivity of the quantitative result to changes in particular variables, such as product volumes, prices, key raw material costs, and so on. (Recall our references to this type of analysis in the earlier chapters.)

The uncertainty of future conditions affecting an investment is the risk of not meeting expectations and being left with an insufficient economic return or even an economic loss-the 
degree of risk being a function of the relative uncertainty about the key variables of the project. Careful estimates and research are often warranted to narrow the margin of error in the predicted conditions on which the analysis is based. Since the basic rationale of making investment relies on a conscious economic trade-off risk versus reward, as we established earlier, the importance of explicitly addressing key areas of uncertainty should be obvious. Identifying key variables will also be helpful in judging the actual performance of the project after implementation, since tracking of these elements is usually much easier than trying to reconstruct the full scope of the project from the accounting records into which it has been merged.

\section{Incremental Cash Flows}

The economic reasoning behind any capital is based strictly on the incremental changes resulting directly from the decision to make the investment, in other words, what is different between the current state of affairs and the situation introduced by the decision in the form of, incremental investment, incremental revenues, incremental costs and expenses.

Moreover, proper economic analysis recognizes only cash flows, that is, the cash effect of positive or negative funds movements caused by the investment.

Any accounting transactions related to the decision but not affecting cash flows are irrelevant for the purpose.

The first basic question to be asked is: What additional funds will be required to carry out the chosen alternative? For example, the investment proposal may, in addition to the outlay for new equipment, entail the sale or other disposal of assets that will no longer be used. Therefore, the decision may actually free some previously committed funds. In such a case, it's the net outlay that counts, after any applicable incremental tax effects have been factored in.

Similarly, the next question is: What additional revenues will be created over and above any existing ones? If an investment results in new revenues, but at the same time causes the loss of some existing revenues, only the net impact, after applicable taxes, is relevant for economic analysis.

The third question concerns the costs and expenses that will be added or removed as a result of the investment. The only relevant items here are those costs, including applicable taxes, that will go up or down as a consequence of the investment decision. Any cost or expense that is expected to remain the same before and after the investment has been made is not relevant for the analysis.

These three questions illustrate why we refer to the economic for analysis of investments as an incremental process. The approach is relative rather than absolute, and is tied closely to carefully defined alternatives and the differences between them. The only data relevant and applicable in any investment analysis are the differential funds commitments as well as differential revenues and costs caused by the decision all viewed in terms of aftertax cash flows.

\section{Relevant Accounting Data}

Investment analysis in large part involves the use data derived from accounting records, not all of which are relevant for the purpose. Accounting conventions that don't involve cash flows must be viewed with extreme caution. This is true particularly with investments that cause changes in operating costs. There we must clearly distinguish between those cost elements that in fact vary with the operation of the new investment and those which only appear to wary. The latter are often accounting allocations which may change in magnitude but do not necessarily represent a true change in costs incurred.

Yet there was likely no actual change in the level of general overhead that can be attributed to the decision to substitute one machine for the other. Therefore, the reported change in the allocation is not relevant for purposes of economic analysis. The analyst must constantly judge whether there has been a change in the true cash outlays and revenues - not whether the accounting system is redistributing existing costs differently. A sound rule that helps avoid being trapped by 
allocations is to avoid unit costs whenever possible and to perform the analysis on the basis of annual changes in costs expected to be caused by the investment decision.

\section{Sunk Costs}

It's a common temptation to include in the analysis of a new investment all or some portion of outlays that occurred in the past, perhaps preparatory to making the new commitment. There's no basis in economic analysis, however, that justifies such backtracking to expenditures that have already been made and that are not recoverable in part or as a whole. Past decisions simply do not count in the economic trade - off underlying a current investment decision. The basic reason for this is that such sunk costs, even if they are connected in some way to the decision at hand, cannot be altered by making the investment now. Economic decisions are always forward - looking and must involve only those things that can be changed by the action being decided. This is the essential test of relevance for any element to be included in the analysis.

\section{The Time Value of Money}

Given the future orientation of investment analysis, the proper application of economic reasoning requires us to recognize the intimate connection between two elements:

- Timing of incremental cash in - flows and outflows.

- The value of cash flows relative to the point of decision.

It's a simple axiom that a dollar received today is worth more than a dollar received one year hence, because we forgo the opportunity of profitably investing today the future dollar we have to wait for. Similarly, spending a dollar a year later is preferable to spending it now, because it can earn a return in the meantime. Thus, the time value of money is related both to the timing of receipt or expenditure, and the opportunity to earn a return on any funds invested.

\section{Components of analysis}

Bearing in mind the strategic perspective and the ground rules just enumerated, we can now turn to the basic components common to all business investment proposals. In essence, capital is invested for one basic reason: to obtain sufficient future economic returns to warrant the original outlay and any related future outlays, that is, sufficient cash receipts over the life of the project to justify the cash spend. This basic trade - off of current cash outflow against expected future cash inflow must be recognized by the analytical methods in one way or another.

To judge the attractiveness of any investment, we must consider the following four elements are the amount expended - the net investment, the potential benefits - the net operating cash inflows, the time period of benefits - the economic life and any final recovery of capital - the terminal value.

A proper economic analysis must take these four elements into account to be able to indicate whether the investment is worthwhile or not.

\section{Net Investment}

The first element in the analysis, the net investment, normally consists of the gross capital requirements for the new assets, reduced by any funds recovered from the trade or sale of existing assets because of the decision. Such recoveries must be adjusted for any change in income taxes arising from a recognized gain or loss on the disposal of existing assets.

\section{Economic Life}

The third element, the time period selected for the analysis, is commonly referred to as the economic life of the investment project. Tor purposes of investment analysis, the only relevant time period is the economic life, as distinguished from the physical life of equipment, or the technological life of a particular process. 
Even though a building or a piece of equipment may be perfectly usable from a physical standpoint, the economic life or the investment is finished if the market for the product or service has disappeared. Similarly, the economic life of any given technology is bound up with the economics of the marketplace - the best process is useless if the resulting product or service can no longer be sold. At that point, any usable resources will have to be repositioned, which requires another investment decision, or they may be disposed of for their recovery value. When redeploying such resources into another project, the net investment for that decision would, of course, be the estimated recovery value after taxes.

\section{Terminal Value}

Normally, if one expects a substantial recovery of capital from eventual disposal of remaining assets at the end of the economic life, these estimated amounts have to be made part of the analysis. Such recoveries can be proceeds from facilities and equipment (beyond the minor scrap value assumed in our example), as well as the release of any working capital associated with the investment. Again, we'll demonstrate the handling of these elements later on.

\section{Methods of Analysis}

Up to this point, I've laid the groundwork for analyzing any business investment by describing the strategic perspective, the decisional framework, and the four essential components of the analysis. My purpose was to demonstrate that analyzing a capital investment is not the simple matter it may appear to be, and we focused on what must be analyzed. I'll now turn to the question of how this is done - the methods and criteria of analysis that will help us judge the economics of the decision.

How do we relate the four basic components such as net investment, operating cash inflow, economic life and terminal value to determine the project's attractiveness? We'll first dispose quickly of some simplistic methods of analysis, which are merely rules of thumb that intuitively grapple with the trade - off between investment and operating cash flows. They are the payback and the simple rate of return, both of which occasionally are still used in practice despite their demonstrable shortcomings.

Our major emphasis in this section will be on measures employing the time value of money, enabling the analyst to deal with relevant cash flows in equivalent terms, that is, regardless of the timing of their incidence. Those key measures are net present value, the profitability index, and the internal rate of return (yield).

Thereafter, I'll turn to basic risk analysis, and discuss the present value payback, annualized net present value, ranges of estimates, simulation, probabilistic reasoning, and risk - adjusted rates.

\section{Payback}

This crude rule of thumb directly relates assumed level annual cash inflows from a project to the net investment required. Using the data from our simplified example, the calculation is straightforward.

\section{Simple Rate of Return}

Again, only passing comments are warranted about this simplistic rule of thumb, which in fact, is the inverse of the payback formula. It states the desirability of an investment in terms of a percentage return on the original outlay. The method shares all of the shortcomings of the payback, because it again relates only two of the four critical aspects of any project, net investment and operating cash flows, and ignores the economic life and any terminal value.

\section{Discounting, Compounding and Equivalence}

I said earlier that common sense tells us a person will not be indifferent between two 
investment propositions that are exactly alike in all aspects except for a difference in timing of the future benefits. An investor will obviously prefer the on providing more immediate benefits. The reason, of course, is that funds available earlier give an individual or a company the opportunity to invest these funds at a profit, be it in a savings account, a government bond, a loan, a new facility, or any one of a great variety of other economic possibilities. Having to wait for a period of time until funds become available entails an opportunity cost in the form of lost earnings potential.

Conversely, common sense also dictates that given the choice between making an expenditure now versus making the same expenditure some time in the future, it's advantageous to defer the outlay. Again, the reason is the opportunity to earn a profit on the funds in the meantime. Stated another way, the value of money is affected directly by two aspects:

- Specific timing of its receipt or disbursement.

- Opportunity of earning a profit during the timing interval.

\section{References:}

1. Garrison, RaymondH. and Erick W. Noreen. Managerial accounting, Concepts for planning, control, decision making $7^{\text {th }}$ edition Homewood, IL.: Richard D Irwin, 1994

2. Dexit and Pndyck, "The option Approach to capital Investment" Harvard business review, May -june '995

3. Shank and Govindarajan. "Strategic Analyisis of Technological Investment" Sloan Management Review, fall 1992 